\title{
Predição e compreensão na leitura de textos literários com sequências narrativas dominantes
}

Vera Wannmacher Pereira ${ }^{\star}$

\section{Resumo}

No presente artigo, disponibilizam-se aos interessados no diálogo teoria, pesquisa e ensino os processos e os resultados de pesquisa realizada com o objetivo de examinar o uso da estratégia de predição e suas relações com o desempenho em compreensão leitora, na leitura de textos literários com sequências narrativas dominantes, e as percepções do leitor sobre o processo realizado. $\mathrm{O}$ estudo, fundado na psicolinguística em associação com a literatura e com o apoio tecnológico na c omputação, teve, como sujeitos, alunos iniciantes e alunos concluintes de um curso de licenciatura em Letras e, como instrumentos de pesquisa, testes de procedimentos preditivos em formato contínuo, testes de procedimentos preditivos em formato segmentado, testes de compreensão e teste de percepções sobre os processos realizados (TPPR). Constituíram-se em resultados principais os instrumentos para análise de procedimentos preditivos (em dois formatos), construídos para esta situação investigativa e a explicitação desses procedimentos (e suas conexões com a com- preensão) diante da leitura de três textos literários por alunos iniciantes e alunos concluintes de um curso de licenciatura em Letras.

Palavras-chave: Leitura. Predição e compreensão. Texto literário.

\footnotetext{
Pós-doutorado em Psicolinguística. Doutorado em Letras (Linguística Aplicada). Professora Permanente do Programa de Pós-Graduação em Letras da PUCRS. vpereira@pucrs.br
}

Data de submissão: mar. 2013 - Data de aceite: maio 2013 http://dx.doi.org/10.5335/rdes.v9i1.3547 


\section{Introdução}

O presente artigo disponibiliza os processos e os resultados de pesquisa realizada com apoio teórico e metodológico na psicolinguística, especificamente nos estudos sobre compreensão e processamento cognitivo da leitura, em conexão com a literatura, com vistas à explicitação da leitura de textos literários. Impulsionado pelas dificuldades de leitura dos alunos de licenciatura em Letras, que repercutem no aprendizado dos conteúdos das diversas disciplinas do curso e na sua atuação como docentes de língua portuguesa, o estudo aqui relatado contribui para o diálogo entre teoria, pesquisa e ensino sobre predição na leitura de textos literários com dominância de sequências narrativas ${ }^{1}$ (AMODEO; PEREIRA, 2010).

Consistiu em objetivo desta pesquisa examinar os procedimentos preditivos utilizados por alunos iniciantes e alunos concluintes de um curso de licenciatura em Letras, durante a leitura de "Betsy", de Rubem Fonseca; "Espírito natalino", de Moacyr Scliar; e "O lobo e o cordeiro", de Millôr Fernandes, bem como sua relação com o desempenho em compreensão leitora e com as percepções desses alunos sobre os processos realizados.

Para tanto, foram construídos instrumentos de pesquisa com vistas à captura desses procedimentos preditivos - em formato contínuo e em formato segmentado -, instrumentos para verificação do desempenho em compreensão leitora dos participantes e instrumentos para análise das percepções dos sujeitos sobre os processos realizados, vinculados a esses dois formatos.

$\mathrm{Na}$ continuidade do artigo, são apresentados o fundo teórico e a pesquisa realizada com os resultados obtidos. Nos comentários finais, são feitas reflexões sobre esses resultados, as relações entre teoria, pesquisa e ensino e as associações entre psicolinguística e literatura com apoio da computação, considerando o processo desenvolvido e as contribuições do trabalho executado.

\section{O fundo teórico}

A chegada a um paradigma de aproximação de áreas de estudo e de teoria, pesquisa e ensino decorre de um percurso de certa extensão e complexidade, marcado por dúvidas, com movimentos de avanços e recuos. As produções científicas sobre a linguagem, com marco inicial no início do século XX, definiram objetos e métodos de estudo distintos para a linguística e para a teoria da literatura. Nessa segmentação, até os anos 60 do século passado, cabia à primeira apenas a realização de estudos sobre a frase e seus constituintes sucessivos e à segunda, de estudos sobre o texto. Naturalmente, o literário. Os demais não eram examinados. Com o surgimento dos estudos linguísticos do texto e do discurso, ocorreu uma gradativa expansão para esses níveis, como unidades de análise, passando seus elementos de organização e funcionamento a ser objetos de estudo. 
Esse avanço, no entanto, não foi suficiente para a aproximação das duas grandes áreas de estudo das Letras. Foi seu desdobramento para o estudo dos gêneros textuais, que, na verdade, consistiu em contribuição mais nítida para isso, na medida em que garantiu para a linguística o texto como objeto de análise, mas ainda com reservas para o texto literário. A possibilidade de superação ocorreu à medida que os estudos psicolinguísticos buscaram interfaces com os do texto e do discurso, estabelecendo uma perspectiva cognitiva para a compreensão e a produção de textos, com um interesse especial pelo literário. Esse direcionamento foi sendo estabelecido pela curiosidade científica de explicitação do processamento cognitivo da compreensão e da produção da plurissignificação. E assim, as hesitações de um lado e de outro vêm se desfazendo, e uma nova perspectiva de estudo do texto literário vem se configurando, materializada em ações convergentes psicolinguística/literatura-estudos, pesquisas, disciplinas, cursos, artigos científicos...

Esse caminho desejado exigiu a construção de metodologias próprias, ganhando relevo, pela qualidade e viabilidade, os protocolos verbais online $e$ offline em sintonia com o uso do computador. Essas possibilidades passaram a realidades efetivas para o desenvolvimento de estudos psicolinguísticos do texto literário. Esse novo componente ampliou por um lado, especificou por outro e instituiu a aproximação psico- linguística e literatura, além do apoio na computação como importante meio, propondo um diálogo entre ciência, arte e tecnologia. É esse diálogo que está subjacente à pesquisa apresentada neste artigo, como pode ser constatado ao longo de sua leitura.

A palavra-chave nessa busca é predição, definida como guessing game por Goodman (1976), sendo nomeada, também, como "jogo de adivinhação", o que, à primeira vista, pode causar estranheza, pois faz parte do nosso universo de crenças, que constitui o senso comum, o ponto de vista de que adivinhar em leitura assume sentidos pouco positivos. Um deles é o de que fazer adivinhações sobre o que está escrito num texto é indicativo de uma leitura apressada, gerando compreensão inadequada. Outro é o de que adivinhar indica leitura superficial. Outro, também, é o de que adivinhar é fazer suposições sem base, conduzindo a conclusões erradas ou pelo menos inconsistentes. Outro, ainda, é o de que adivinhar significa imaginar sem apoio no texto. Esses entendimentos definem o leitor como descomprometido e desinteressado e o resultado da leitura como dissociado do que o texto apresenta. Há que se considerar, no entanto, que a adivinhação psicolinguística tem apoio nos elementos linguísticos do texto e nos conhecimentos prévios do leitor, realizando-se na conexão entre este, 0 autor e o texto, numa dada situação.

Acrescenta-se como dúvida o recorte da leitura com apoio no computador, 
uma vez que, com frequência, há, na família, na escola, na sociedade em geral, a conviç̧ão de que esse artefato é um dos grandes obstáculos para que os estudantes gostem de ler, o que não procede (AMODEO; PEREIRA, 2010). Dado que seu uso depende de que o usuário seja razoavelmente hábil em leitura, conta com o uso de processos cognitivos, linguísticos e interativos de leitura importantes. Diante disso, não pode ser negada a existência de um equipamento atraente e que traz em si a possibilidade de constituir-se em elemento instigador do desejo de ler e, o mais importante, orientador do processo de ler. Paralelamente, o computador, por meio dos softwares, dispõe de recursos para registro do processamento da leitura, desde que delimitados e programados para os objetivos traçados (PEREIRA; PICCINI, 2006). No caso do estudo aqui relatado, ele é utilizado como meio que permitiu a organização dos instrumentos de pesquisa em formato contínuo e em formato segmentado.

Do mesmo modo, a aproximação entre teoria, pesquisa e ensino consiste numa busca na história das definições sobre conhecimento. Desde os grandes pensadores gregos, uma divisão se estabeleceu sobre a origem do conhecimento - na mente ou na experiência. Nessa trilha, ainda há os que consideram mais erudito o primeiro ponto de vista, embora os estudos empíricos estejam a revisar as concepções racionalistas e a impulsionar os grandes achados científicos nas mais diversas áreas. A chegada a um entendimento desse tema como necessariamente dialético vem tendo suas demoras e aumenta suas travas para inclusão do ensino. Uma dessas travas está na definição do papel de quem pesquisa e do papel de quem ensina, o que provoca um afastamento entre o pesquisador e 0 professor. As dúvidas sobre a consistência acadêmica de um caminho que faça essa aproximação e sobre sua adequação para estudiosos da linguística e da literatura vêm ganhando novos contornos a partir dos avanços dos estudos cognitivos que têm direcionado seu olhar para o aprendizado. A psicolinguística, por sua vez, vem se definindo como uma ciência voltada para o desvendamento dos processos de comunicação, especialmente de leitura e de escrita, portanto com condições de se estabelecer como âncora para a descoberta de caminhos para o ensino. Entre suas grandes contribuições está, então, a possibilidade de iluminar os estudos que aproximam pesquisa, aprendizado e ensino, conferindo-lhes estatuto acadêmico nobre.

Nesse espaço de dúvidas e estranhamentos, uma certeza se estabelece - a psicolinguística e a literatura têm muito a fazer para explicitar, por meio de pesquisas associadas, como os leitores processam o texto literário. Para isso, a concepção de leitura apoia-se nos estudos sobre processamento cognitivo, segundo os quais a predição, também denominada adivinhação, antecipação, previsão, consiste em movimento significativo 
utilizado pelo leitor diante do texto, observando seus elementos fônicos, morfossintáticos, semânticos, pragmáticos e textuais (GOMBERT, 1992).

Esse conceito está vinculado a uma estratégia de leitura definida por Goodman (1991) e Smith (2003) - a predição, sendo a mais presente nas diversas categorizações que tratam do assunto. Consiste num jogo psicolinguístico em que o leitor, com base nos conhecimentos prévios que possui sobre o assunto e sobre a língua em questão e com apoio nas pistas linguísticas deixadas pelo autor no texto, faz adivinhações, antecipações, previsões, enfim predições sobre conteúdos do texto ainda não lidos.

Percebida de um modo mais amplo, a predição é uma estratégia de compreensão dos fatos, das experiências que vivemos, enfim, do mundo, que é objeto constante de nossas leituras. Sem praticar a predição, a antecipação, talvez não conseguíssemos sequer apostar em um futuro e nos organizarmos para vivê-lo.

Diante de um texto, o leitor realiza um verdadeiro exercício de apostas, um jogo instigante que associa dados do texto/contexto, informações já presentes nele (leitor) e emoções produzidas por seu cérebro, possibilitando-lhe, assim, a compreensão do material escrito, o estabelecimento de relações com o mundo e o desenvolvimento de reflexões metacognitivas sobre o próprio processo, a leitura realizada e o conhecimento construído (PEREIRA, 2002). Trata-se de uma estratégia de grande relevância no processo de leitura, podendo ser considerada de grande amplitude (PEREIRA, 2012), na medida em que abrange outras estratégias mais específicas. Em estudo realizado por Pereira e Piccini (2006), os autores, ao pesquisarem experimentalmente o uso dessa estratégia, definiram-na como constituída do automonitoramento, da autoavaliação e da autocorreção. Isso significa que o percurso cognitivo da adivinhação exige do leitor um nítido processo de consciência, que supõe período continuado de atenção (DEHAENE, 2007): a) que esteja atento não apenas às pistas linguísticas do texto e aos seus conhecimentos prévios, mas também às antecipações de leitura que realiza; b) que mantenha seu foco de atenção nessas antecipações, avaliando-as do ponto de vista de sua pertinência às pistas e aos conhecimentos prévios; $\mathrm{c}$ ) que modifique essas antecipações, caso as julgue impróprias.

Está, na base da estratégia de predição, a de inferência (PEREIRA, 2009). Isso significa que, para decodificar um texto, para compreendê-lo, para estabelecer relações desse material escrito com o mundo, para construir emoções, para chegar à satisfação com a leitura, inferências de diferentes níveis de complexidade, exigindo diferentes graus de esforço cognitivo, são condições indispensáveis. Certamente as inferências para decodificação dos sinais gráficos de um texto, cujo código é de domínio do leitor, são menos complexas do que as inferências para entendimento de 
uma metáfora ou para estabelecimento de conexões entre fatos da história, ou, ainda, para deciframento do enigma-chave da narrativa.

O processo de adivinhação está vinculado não a um simples desejo do leitor, mas ao desejo de toda a situação de leitura, incluindo: esse leitor, com seus conhecimentos prévios, seu estilo cognitivo, seu objetivo de leitura; o texto com seu lugar social, suas sequências dominantes e pistas linguísticas deixadas por quem $o$ escreveu (ADAM, 2008); o autor, com sua história, conhecimentos e peculiaridades de sua proposta de escrita; o momento de criação e o de leitura; e o suporte de veículo do texto.

A configuração da situação de leitura define as rotas de predição e $o$ modo de percorrê-las. Considerando as características do texto, as predições do leitor devem apoiar-se, no caso de uma história, mais fortemente no encadeamento narrativo e na movimentação das personagens, enquanto, no caso de um editorial, nas relações entre a tese e os argumentos. Considerando o objetivo de leitura, como a simples busca de uma informação específica (uma data, uma expressão, um local...) num texto de divulgação científica, as antecipações do leitor são realizadas nessa direção. Considerando o portador de veiculação de uma notícia (um determinado jornal de circulação), as predições do leitor são realizadas com base no perfil desse portador. Considerando os conhecimentos prévios, se o leitor dispuser de poucos sobre o conteúdo do texto, caber-lhe-á apoiar, predominantemente, suas predições nas pistas linguísticas.

Como explicitado até aqui, adivinhar é relevante, e o modo de fazer antecipações é marcado pela situação de leitura em todos os seus componentes (PEREIRA, 2012), o que define esse processo não apenas como uma probabilidade, mas também como uma certeza, concepção que norteia o presente artigo.

Essa engenhosidade do percurso de compreensão permite levantar a hipótese de considerar a adivinhação como a mais desejável estratégia de leitura de todas as manifestações textuais, cabendo, no entanto, lugar especial para o texto literário, dada sua polissemia, uma vez que a antecipação instiga o leitor a dirigir sua atenção para a linguagem do texto, para os dados do contexto, para os seus próprios conhecimentos prévios, a realizar movimentos cognitivos inferenciais para compreensão dos implícitos e, assim, a se aproximar da história, do autor, das personagens, enfim, da composição imaginação/realidade, como um momento de deciframentos e emoções próprias.

Considerando que a natureza do texto constitui-se em importante variável definidora dos modos de leitura, essa influência marca, também, fortemente, o processo de antecipação. Desse modo, diante do texto literário, o leitor, na busca da compreensão, da fruição imaginativa, da vivência do estético, desenvolve procedimentos antecipatórios pertinen- 
tes a essa busca. É interessante que todas essas concepções estão presentes em definições desenvolvidas pela teoria da literatura de algum modo, indicando a pertinência da aproximação com a psicolinguística, especialmente no que se refere ao processamento cognitivo da leitura, envolvendo estratégias, compreensão, consciência e metacognição.

A concepção de literatura como aberta aos múltiplos entendimentos (CULLER, 1999) exige tratar cada leitor como um leitor único e cada leitura como uma leitura própria. Do ponto de vista psicolinguístico, tal entendimento se afirma na medida em que o processo de leitura se realiza por meio de sinapses, que são individuais e ocorrem não como simples repetição linear, mas como transformação das já realizadas.

Está presente, nas definições teóricas da literatura, a inclusão de autor, leitor, texto, sendo definido pelo primeiro o que vai deixar mais ou menos explícito. A leitura desses traços está, ao mesmo tempo, no texto e no leitor, uma vez que, do ponto de vista psicolinguístico, este deve acionar as pistas linguísticas do texto e os seus próprios conhecimentos prévios (SMITH, 2003), apoios para a realização dos procedimentos preditivos, que oportunizam a reconstituição continuada do horizonte de expectativas do leitor (JAUSS, 1993).

A visão não maniqueísta da leitura literária (ECO, 1993) constrói um alicerce para a perspectiva psicolinguística, pois, segundo esta, o entendimento do texto renova-se a cada sinapse, o que torna inaceitáveis uma só compreensão e um só caminho para chegar a ela, tornando desejáveis, pois basilares do entendimento, os procedimentos preditivos.

Para a construção desses caminhos cognitivos preditivos, as pistas linguísticas são consideradas indispensáveis pela psicolinguística, o que foi, de certo modo, antecipado por Ingarden (1965), ao definir os estratos do texto literário e considerá-los estruturalmente fundantes. Tal entendimento é gerado no reconhecimento da consciência como indispensável para a construção dos sentidos, o que, para a psicolinguística, é questão nuclear.

Nesse recorte de observação da leitura do texto literário, o estudo aqui relatado foi desenvolvido com o propósito de examinar especificamente a compreensão, os procedimentos preditivos de leitores iniciantes e concluintes de um curso de licenciatura em Letras e suas próprias percepções sobre esses procedimentos, por ocasião da leitura de textos literários de sequências narrativas dominantes. Para isso, tomou como alicerce um corpo de definições psicolinguísticas sobre processamento cognitivo que encontram importantes concepções convergentes na teoria da literatura.

\section{A pesquisa e os resultados}

Considerando esse objetivo, a pesquisa foi desenvolvida de modo a responder à seguinte indagação: quais as relações 
entre os procedimentos preditivos dos sujeitos, os seus escores de compreensão e suas percepções sobre os processos desenvolvidos, por ocasião da leitura de textos literários com sequências narrativas dominantes, considerando a situação dos sujeitos no seu curso de licenciatura em Letras?

O processo de investigação foi organizado com vistas a obter as informações necessárias para responder a essa indagação, caracterizando-se como de natureza quantitativa e qualitativa, de associação teoria, pesquisa e ensino, de aproximação entre psicolinguística e literatura e de apoio tecnológico na computação.

Para o desenvolvimento da pesquisa, foram selecionados três textos literários com sequências narrativas dominantes, exigindo do leitor, para sua compreensão, a continuada formulação e testagem de predições: "Betsy", de Rubem Fonseca; "Espírito natalino", de Moacyr Scliar; e "O lobo e o cordeiro", de Millôr Fernandes.

Definidos os textos, foram construídos os instrumentos de investigação: os testes de compreensão leitora, com itens sobre conteúdos de cada texto, os testes de conhecimentos preditivos em formato contínuo e os testes de conhecimentos preditivos em formato segmentado, contendo questionamentos sobre predições do leitor e o teste de percepções, apresentando questões sobre os processos realizados pelo leitor.
A aplicação dos testes ocorreu com doze sujeitos, sendo um grupo com seis alunos iniciantes e um grupo com seis alunos concluintes de um curso de licenciatura em Letras. De cada grupo, foram definidos três sujeitos para texto em formato contínuo e três para texto em formato segmentado, programados para projeção no computador.

O processo de coleta de dados ocorreu individualmente com cada sujeito. Os testes de conhecimentos preditivos, organizados para cada texto e em dois formatos, foram aplicados do seguinte modo: no formato segmentado, os sujeitos receberam o texto em segmentos previamente definidos, fizeram a leitura de cada um, interromperam, verbalizaram as predições e teceram comentários sobre a base dessas predições. Era, também, esperado que correlacionassem as predições sucessivas, ao longo da leitura, confirmando-as ou corrigindo-as. No outro formato, os textos eram apresentados em sua forma contínua, sendo os sujeitos, igualmente, estimulados a verbalizar suas predições e a fazer comentários. Todas as leituras e comentários dos sujeitos foram gravados e, posteriormente, transcritos. Após a aplicação dos testes de procedimentos preditivos, os sujeitos responderam aos testes de compreensão leitora e ao teste de percepções sobre os processos realizados.

Os dados coletados junto a 12 sujeitos, por meio dos testes de compreensão leitora, para os dois grupos (I: iniciantes; $\mathrm{C}$ : concluintes), para os dois formatos (C: 
contínuo; S: segmentado) e para os três 1, onde 1 indica acerto e 0, erro. Após, textos, estão apresentados na Tabela seguem-se as análises.

Tabela 1 - Resultados dos testes de compreensão leitora

\begin{tabular}{|c|c|c|c|c|c|c|c|c|c|c|c|c|c|c|}
\hline & eitos & S1 & S2 & S3 & S4 & S5 & S6 & S7 & S8 & S9 & $\mathrm{S} 10$ & $\mathrm{~S} 11$ & S12 & \\
\hline $\mathrm{Pe}$ & $\begin{array}{l}\text { do do } \\
\text { rso }\end{array}$ & I & C & C & 1 & I & I & C & C & I & C & I & C & Total \\
\hline & nato & C & $S$ & C & $S$ & $S$ & $S$ & $S$ & C & $C$ & C & C & S & \\
\hline 0 & Q1 & 1 & 0 & 1 & 0 & 1 & 1 & 0 & 1 & 0 & 0 & 1 & 0 & 6 \\
\hline 융 웅 & Q2 & 0 & 1 & 1 & 0 & 1 & 1 & 0 & 0 & 0 & 0 & 1 & 0 & 5 \\
\hline 00 & Q3 & 1 & 0 & 1 & 0 & 1 & 1 & 1 & 0 & 1 & 1 & 0 & 1 & 8 \\
\hline & Q4 & 0 & 1 & 1 & 1 & 1 & 1 & 0 & 1 & 1 & 1 & 1 & 1 & 10 \\
\hline : & Q5 & 1 & 1 & 0 & 0 & 1 & 1 & 1 & 1 & 0 & 0 & 0 & 1 & 7 \\
\hline & Q6 & 0 & 0 & 1 & 1 & 1 & 1 & 1 & 1 & 1 & 1 & 1 & 1 & 10 \\
\hline & Q7 & 1 & 1 & 1 & 1 & 1 & 0 & 1 & 1 & 0 & 1 & 1 & 1 & 10 \\
\hline$\frac{\bar{s}}{0}$ & Q8 & 0 & 1 & 0 & 0 & 0 & 0 & 0 & 0 & 0 & 1 & 0 & 0 & 2 \\
\hline & Q9 & 1 & 1 & 1 & - & 1 & 1 & 1 & 1 & 1 & 1 & 1 & 1 & 11 \\
\hline & Total & 5 & 6 & 7 & 3 & 8 & 7 & 5 & 6 & 4 & 6 & 6 & 6 & 69 \\
\hline
\end{tabular}

Obs.: O campo "Período do curso" indica se o sujeito é iniciante (I) ou concluinte (C) no curso de Letras, e o campo "Formato" indica se o sujeito leu o texto em formato contínuo (C) ou segmentado (S).

Observando o conjunto dos 12 sujeitos e os dados decorrentes da aplicação em todas as situações, evidencia-se um total de 69 acertos. Essa soma representa $63,8 \%$ do total possível (108 acertos). Realizando um recorte no formato do teste de leitura, é possível verificar que os sujeitos que leram os textos em formato contínuo (S1, S3, S8, S9, S10, S11) alcançaram, respectivamente, escores de $5,7,6,4,6,6$, o que totalizou 34 acertos. Os sujeitos que leram os textos em formato segmentado (S2, S4, S5, S6, S7, S12) atingiram, respectivamente, $6,3,8,7,5,6$, totalizando 35 acertos. Esses dados mostram que o formato segmentado apresentou escores mais altos, mas com diferença mínima em relação ao contínuo, indicando que o formato pouco influenciou a compreensão leitora dos sujeitos.

Examinando os dados do ponto de vista da posição dos sujeitos no curso, constata-se que os sujeitos do grupo 
dos iniciantes ( $\mathrm{S} 1, \mathrm{~S} 4, \mathrm{~S} 5, \mathrm{~S} 6, \mathrm{~S} 9, \mathrm{~S} 11)$ fizeram, respectivamente, $5,3,8,7,4,6$ pontos, somando 33. Os sujeitos do grupo dos concluintes (S2, S3, S7, S8, S10, $\mathrm{S} 12)$, por sua vez, alcançaram escores respectivos de $6,7,5,6,6,6$, somando 36 pontos. A comparação desses dados mostra que os sujeitos concluintes tiveram escores mais elevados do que os iniciantes, embora com diferença pequena.

Dirigindo a atenção para os dados de cada texto, é possível constatar que os escores mais altos ocorreram na leitura do "Espírito natalino" (27 acertos), enquanto na leitura dos demais os escores foram de 23 acertos para "Betsy" e 19 acertos para "O lobo e o cordeiro". Observando a posição dos sujeitos no curso, é possível verificar que o grupo de concluintes teve escores mais altos do que os iniciantes em "Espírito natalino" e em "Betsy", ocorrendo o inverso em "O lobo e o cordeiro". Considerando o formato do instrumento, constata-se que os sujeitos que leram em formato contínuo tiveram escores mais altos do que os que leram no formato segmentado em "O lobo e o cordeiro" e em "Betsy", embora com pequena diferença.

Esses dados levantados indicam como mais positivamente associados à compreensão leitora o texto "Espírito natalino", o grupo dos sujeitos concluintes e o formato segmentado, embora com diferenças muito pequenas. Apontam como menos positivamente associados à compreensão leitora o texto "O lobo e o cordeiro", o grupo dos sujeitos iniciantes e o texto em formato contínuo.

Prosseguindo a análise, são apresentados, na Tabela 2, os dados referentes à aplicação dos testes de conhecimentos preditivos (S: sim; N: não), para os três textos, nos dois formatos - contínuo e segmentado (C: contínuo; S: segmentado) e nos dois grupos de sujeitos (I: iniciantes; C: concluintes).

Tabela 2 - Resultados dos testes de procedimentos preditivos

\begin{tabular}{|c|c|c|c|c|c|c|c|c|c|c|c|c|c|c|}
\hline & & Sujeitos & S1 & S2 & S3 & S4 & S5 & S6 & S7 & S8 & S9 & S10 & S11 & S12 \\
\hline & & eríodo do curso & 1 & $\mathrm{C}$ & $\mathrm{C}$ & 1 & 1 & I & $\mathrm{C}$ & $\mathrm{C}$ & I & $\mathrm{C}$ & 1 & $\mathrm{C}$ \\
\hline & & Formato & $\mathrm{C}$ & $\mathrm{S}$ & C & $S$ & $S$ & $S$ & $S$ & $\mathrm{C}$ & C & C & $\mathrm{C}$ & $S$ \\
\hline$\circ \stackrel{\circ}{0}$ & 음 & Pistas linguísticas & $\mathrm{S}$ & $\mathrm{S}$ & $\mathrm{S}$ & $\mathrm{S}$ & $\mathrm{S}$ & $\mathrm{S}$ & $\mathrm{S}$ & $\mathrm{S}$ & $\mathrm{S}$ & $\mathrm{S}$ & $\mathrm{S}$ & $\mathrm{S}$ \\
\hline 응 훙 & 这 & Conhecimentos prévios & & $S$ & & & & S & & & & S & & S \\
\hline 00 & & Automonitoramento & $\mathrm{N}$ & $S$ & $S$ & $\mathrm{~N}$ & $S$ & $\mathrm{~N}$ & $S$ & $\mathrm{~N}$ & $\mathrm{~N}$ & $S$ & $S$ & $S$ \\
\hline 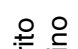 & 응 형 & Pistas linguísticas & $S$ & $S$ & S & $S$ & $S$ & $S$ & $S$ & S & $S$ & $S$ & $S$ & $S$ \\
\hline$\frac{\bar{\alpha}}{\infty} \frac{\bar{\pi}}{\pi}$ & 운 & Conhecimentos prévios & & $S$ & & & & & $S$ & & & & & S \\
\hline & & Automonitoramento & $\mathrm{N}$ & $\mathrm{s}$ & $\mathrm{s}$ & $\mathrm{s}$ & $\mathrm{s}$ & $\mathrm{s}$ & $\mathrm{s}$ & $\mathrm{N}$ & $\mathrm{N}$ & S & $\mathrm{S}$ & $\mathrm{S}$ \\
\hline के & & Pistas linguísticas & $\mathrm{S}$ & $S$ & $S$ & $S$ & $S$ & $S$ & $S$ & $S$ & $S$ & $S$ & $S$ & $S$ \\
\hline$\infty$ & & Conhecimentos prévios & & & & & & & & & & $\mathrm{S}$ & & $\mathrm{S}$ \\
\hline & & Automonitoramento & $\mathrm{S}$ & S & $\mathrm{S}$ & $\mathrm{S}$ & $\mathrm{S}$ & $\mathrm{N}$ & $\mathrm{S}$ & $\mathrm{S}$ & $\mathrm{S}$ & $\mathrm{S}$ & $\mathrm{S}$ & $\mathrm{S}$ \\
\hline
\end{tabular}

Legenda: S: sim; N: não 
A Tabela 2 mostra que os 12 sujeitos apoiaram suas predições em pistas linguísticas, tanto os do grupo de iniciantes como os do grupo de concluintes, ocorrendo isso nos três textos, nos dois formatos.

O uso de conhecimentos prévios para predizer ocorreu com quatro sujeitos em "O lobo e o cordeiro", três em "Espírito natalino" e dois em "Betsy". Desses nove casos, oito referem-se a alunos concluintes.

No que diz respeito ao formato, dos nove sujeitos que utilizaram os conhecimentos prévios para predizer, sete eram associados ao formato segmentado. $\mathrm{O}$ uso de pistas linguísticas ocorreu com todos os sujeitos, indicando não haver associação específica.

Quanto ao automonitoramento, é possível constatar que os sujeitos, em sua maioria, garantiram suas predições utilizando-o, o que ocorreu com maior frequência em "Betsy" (onze) e em "Espírito natalino" (oito), tendo sido menos frequente em "O lobo e o cordeiro" (sete).

No que se refere ao formato, em " $\mathrm{O}$ lobo e o cordeiro", quatro sujeitos que leram no segmentado utilizaram o automonitoramento, tendo ocorrido isso com três no contínuo. Em "Espírito natalino", seis sujeitos utilizaram o automonitoramento no formato segmentado e três no formato contínuo. Em "Betsy", cinco utilizaram essa estratégia em formato segmentado e seis em formato contínuo. Desse modo, apenas neste, o uso do automonitoramento esteve mais associado ao formato contínuo, assim como em "Espírito natalino" a maior frequência foi no formato segmentado.

Os dados da Tabela 2 indicam que os procedimentos preditivos estiveram associados ao apoio predominante em pistas linguísticas e ao uso de automonitoramento. Cabe referir, também, que o uso de conhecimentos prévios ocorreu mais com os alunos concluintes e que o formato segmentado favoreceu o uso desses procedimentos de leitura.

Dando continuidade à análise, segue a Tabela 3, com os resultados do teste de percepções sobre os processos realizados. 
Tabela 3 - Resultados do teste de percepções sobre os processos realizados

\begin{tabular}{|c|c|c|c|c|c|c|c|c|c|c|c|c|}
\hline & S1 & $\mathrm{S} 2$ & S3 & S4 & S5 & S6 & S7 & S8 & S9 & S10 & $\mathrm{S} 11$ & $\mathrm{~S} 12$ \\
\hline Período do curso & I & $\mathrm{C}$ & $\mathrm{C}$ & $\mathrm{I}$ & $\mathrm{I}$ & I & C & $\mathrm{C}$ & 1 & C & I & $\mathrm{C}$ \\
\hline Formato & C & $\mathrm{S}$ & C & $S$ & $\mathrm{~S}$ & $\mathrm{~S}$ & $\mathrm{~S}$ & C & C & C & C & $S$ \\
\hline Q1 & e & e & $d$ & $d$ & $d$ & $d$ & e & e & e & $d$ & e & d \\
\hline Q2 & e & e & $d$ & $d$ & $\mathrm{e}$ & $d$ & d & e & e & e & $d$ & e \\
\hline Q3 & $d$ & e & $d$ & $\mathrm{e}$ & e & c & $b$ & $d$ & $d$ & e & $d$ & e \\
\hline Q4 & e & $d$ & a & $d$ & c & c & $\mathrm{a}$ & $d$ & c & e & a & d \\
\hline Q5 & $d$ & e & $d$ & $\mathrm{e}$ & e & $d$ & e & e & $d$ & e & $d$ & $\mathrm{~d}$ \\
\hline Q6 & e & - & $d$ & $d$ & e & e & $a$ & $c$ & $d$ & e & e & e \\
\hline Q7 & $a$ & $d$ & $d$ & $\mathrm{e}$ & $c$ & $d$ & $\mathrm{a}$ & $d$ & e & e & $d$ & $\mathrm{~d}$ \\
\hline Q8 & $d$ & $d$ & $d$ & $\mathrm{~b}$ & $c$ & $d$ & $a$ & $d$ & $b$ & $d$ & $d$ & $\mathrm{a}$ \\
\hline Q9 & $d$ & $d$ & $d$ & e & $\mathrm{e}$ & $\mathrm{e}$ & $d$ & e & $\mathrm{d}$ & e & $d$ & $\mathrm{e}$ \\
\hline Q10 & 8 & 8 & 8 & 10 & 7 & 8 & 7 & 8 & 7 & 10 & 6 & 9 \\
\hline Legenda: $\begin{aligned} & \mathrm{a}=\text { discordo } \\
& \mathrm{b}=\text { discordo } \\
& \mathrm{c}=\text { indiferent } \\
& \mathrm{d}=\text { concordo } \\
\mathrm{e} & =\text { concordo }\end{aligned}$ & Imer & & & & & & & & & & & \\
\hline
\end{tabular}

O TPPR possibilitou conhecer as percepções dos sujeitos sobre o trabalho realizado e sobre os próprios processos de compreensão leitora no que se refere, especificamente, ao uso da predição.

Segundo as respostas às questões $1 \mathrm{e}$ 2 , os 12 sujeitos estiveram de acordo (ou totalmente ou parcialmente) com a afirmativa de que "as pistas linguísticas e as pistas contextuais foram determinantes para a predição do que aconteceria a seguir".

As respostas às questões 3,4 e 5 permitiram verificar o que os sujeitos consideravam, se os textos escolhidos teriam favorecido a realização de predições. A análise dessas respostas apontou como mais favorável "O lobo e o cordeiro", seguido de "Espírito natalino" e de "Betsy".
A sexta questão foi diferente para os leitores, dependendo de terem lido os textos, ou no formato segmentado, ou no formato contínuo. Os seis sujeitos que leram os textos no formato segmentado (S2, S4, S5, S6, S7 e S12) consideraram, predominantemente, que o texto apresentado aos poucos, em segmentos sucessivos, favoreceu a reflexão sobre os procedimentos preditivos. Para eles, o espaço entre um segmento e outro, promovido pela configuração da situação de leitura criada para a aplicação do instrumento, foi frutífero para o leitor fazer uma aposta e tentar predizer conteúdos ainda não lidos no texto. Para os cinco dos seis sujeitos que leram o texto no formato contínuo ( $\mathrm{S} 1, \mathrm{~S} 3, \mathrm{~S} 8, \mathrm{~S} 9$, $\mathrm{S} 10$ e S11), o texto apresentado em sua 
totalidade favoreceu a reflexão sobre os procedimentos preditivos. Desse modo, os dois formatos foram considerados favoráveis para a realização de predições.

Na sétima questão ("As suas reflexões sobre os procedimentos preditivos ocorreram de forma natural - sem motivação do monitor"), nove sujeitos concordaram com essa asserção e dois discordaram totalmente, sendo um iniciante (S1) e um concluinte (S7).

Em relação à oitava questão ("As suas reflexões ocorreram de forma estimulada - com motivação do monitor"), sete sujeitos concordaram parcialmente com essa afirmação e quatro discordaram total ou parcialmente dela, o que mostrou contradição em relação à questão anterior, denotando falta de clareza acerca dos processos metacognitivos.

Na nona questão ("A leitura e a reflexão sobre os processamentos preditivos dos textos foram satisfatórias"), todos concordaram total ou parcialmente, indicando certa fragilidade nos processos reflexivos.

A décima questão ("Dê uma nota de 1 a 10 em relação à sua reflexão sobre procedimentos preditivos") revelou dois sujeitos $100 \%$ satisfeitos com seu próprio desempenho, um iniciante e um concluinte; três sujeitos com nota 7 , sendo dois deles iniciantes; um sujeito iniciante com uma nota menor que 7; e os demais com notas 8 ou 9 .

Com base nos resultados decorrentes da aplicação dos instrumentos, expostos até aqui, tornou-se possível responder à questão central de pesquisa, o que é realizado a seguir.

$\mathrm{Na}$ análise, foram considerados como procedimentos preditivos o uso das pistas linguísticas, o uso dos conhecimentos prévios e a realização do automonitoramento. Foi constatado que todos utilizaram pistas linguísticas, sendo que, em nove de 36 situações, foram utilizados os conhecimentos prévios como apoio. Esses dados estão, possivelmente, associados ao fato de serem alunos de um curso de Letras em que há, continuadamente, a orientação dos professores sobre a importância da linguagem, além de haver uma disposição do estudante para o estudo da língua. Em relação ao automonitoramento, foi utilizado em vinte e sete situações, enquanto em nove isso não ocorreu, o que pode estar relacionado às mesmas razões já apontadas. $\mathrm{O}$ automonitoramento foi mais realizado pelos concluintes (16), em comparação aos iniciantes (11). Considerando os textos, esse procedimento preditivo foi mais utilizado em "Betsy" (11), sendo que, em "Espírito natalino", ocorreu em nove situações e, em "O lobo e o cordeiro", sete. O escore mais alto em "Betsy" pode estar associado à densidade e à presença de implícitos nesse texto. No que se refere aos formatos, o automonitoramento foi mais utilizado no segmentado (15), do que no contínuo (10). Esse resultado está dentro do esperado, considerando que o formato segmentado, possivelmente, estimule mais a reflexão metacognitiva. No que se refere aos conhecimentos prévios, os concluintes os 
utilizaram em oito situações, enquanto, entre os iniciantes, houve apenas uma situação de uso, o que se explica, provavelmente, pelo fato de os concluintes já terem armazenado mais conhecimentos. No que se refere ao formato dos instrumentos, houve duas ocorrências de uso de conhecimentos prévios no contínuo e de sete no segmentado. Essa situação pode ser explicada pelo fato de o formato sugerir uma reflexão metacognitiva.

Segundo os dados levantados sobre compreensão leitora, os alunos iniciantes, em sua totalidade, obtiveram um escore de 33 pontos e os concluintes de 36 pontos, indicando, conforme previsto, um desempenho mais favorável entre os concluintes, embora com pequena diferença. Considerando o formato dos instrumentos (contínuo e por segmento), os dados evidenciam pouca diferença entre os dois formatos, com 34 para o contínuo e 35 para o segmentado, o que significa que o formato pouco influenciou os escores de compreensão leitora. Do ponto de vista dos textos, os escores de compreensão mais elevados ocorreram na leitura de "Espírito natalino" (27). Nos outros textos os escores foram mais baixos: "Betsy" (23) e "O lobo e o cordeiro" (19). Confrontando esses três grupos de dados, o texto "Espírito natalino" teve maior influência, talvez por apresentar características mais próximas aos textos trabalhados no curso.

Os dados referentes às percepções dos sujeitos indicam que, segundo eles, os procedimentos preditivos foram favorecidos tanto no formato contínuo como no segmentado. Do mesmo modo, apontam que, nos três textos utilizados, esses procedimentos foram favorecidos. Essa perspectiva repetiu-se, também, em relação ao uso de pistas linguísticas. Além disso, os dados demonstram que os procedimentos preditivos realizados pelos sujeitos foram positivos, evidenciando, desse modo, um nível de reflexão pouco discriminativo.

O cruzamento dos dados permitiu identificar algumas relações de forma a responder à questão central de pesquisa. Considerando os sujeitos que alcançaram escores mais altos de compreensão, pode ser apontada uma relação entre o uso de procedimento preditivo de automonitoramento e o desempenho alcançado pelo sujeito. Os escores de compreensão estão pouco associados à posição dos sujeitos no curso, uma vez que a diferença de escores é pequena, embora favorável ao grupo de concluintes. Em relação ao formato do instrumento, o segmentado foi mais favorável à compreensão, considerando que, dos três com escores mais altos, dois incluem-se nesse grupo, embora com diferença mínima entre os dois grupos. Quanto ao texto de leitura, verificou-se uma associação em relação à compreensão e ao uso de automonitoramento, na medida em que os desempenhos foram mais produtivos em "Espírito natalino" e em "Betsy", textos com características mais trabalhadas durante o curso.

No que se refere às suas percepções sobre os processos realizados, os sujeitos 
reconheceram a importância da realização de predições e consideraram que "O lobo e o cordeiro" é o texto que mais favorece esses procedimentos. No entanto, há certa incongruência com outras respostas, indicando certa indefinição no uso de processos metacognitivos. Desses dados, parece que a correlação que se evidencia mais positivamente é entre escores altos de compreensão, uso de pistas linguísticas, conhecimentos prévios e automonitoramento, leitura em formato segmentado, grupo de concluintes e os textos "Espírito natalino" e "Betsy".

\section{Considerações finais}

Neste momento, cabe tecer considerações referentes aos resultados e às associações teóricas e metodológicas norteadoras da pesquisa.

Os resultados expostos no item anterior indicam algumas diferenças importantes, considerando a posição dos sujeitos no curso de Letras - os estudantes concluintes com desempenho em compreensão mais favorável do que os iniciantes, mas não com a diferença desejável, assim como apoio um pouco mais frequente das predições nos conhecimentos prévios e no automonitoramento. Esses resultados apontam para a necessidade de fortalecer, durante o curso, o uso da estratégia de predição leitora com textos literários de sequências narrativas dominantes. Trata-se de importante identificação, tendo em vista que pode trazer contribuições para o aprendizado da leitura dos estudantes e para seu preparo com vistas à docência nas escolas.

O conjunto de informações armazenadas durante o processo de investigação permite afirmar que o uso de procedimentos preditivos na leitura de textos literários com sequências narrativas dominantes e a consciência sobre seu uso trazem benefícios para a compreensão, fazendo da leitura não uma mera decodificação, mas um processo dinâmico de interação entre leitor, autor e texto, dentro de uma dada situação. Mostram, também, que a apresentação do texto em segmentos sucessivos pode contribuir para isso, sugerindo esse procedimento como caminho não só de pesquisa, mas também de ensino.

No que se refere às associações entre teoria, pesquisa e ensino, o estudo aqui relatado foi desenvolvido nesse ponto de vista. O fundo teórico teve como eixo o processamento cognitivo da leitura com foco na estratégia de predição, caracterizada por movimentos de antecipação, previsão, adivinhação. Esse eixo deu sustentação ao design da pesquisa, que contou com ferramentas computadorizadas ad hoc, possibilitando a obtenção de dados sobre procedimentos preditivos, compreensão leitora e percepções dos sujeitos diante de textos literários com sequências narrativas dominantes. O fundo teórico e os dados empíricos da pesquisa estiveram voltados para o aprendizado e o ensino, considerando constituírem-se os sujeitos em estudan- 
tes iniciantes e concluintes de Letras. Essas associações permitiram a identificação de pontos importantes, evidenciados nesse âmbito de ensino que exigem atenção - ampliação do espectro de textos literários com sequências narrativas dominantes e desenvolvimento de metodologia de ensino da leitura desses textos, com ênfase no uso de procedimentos preditivos para a compreensão leitora - uso de pistas linguísticas e conhecimentos prévios e realização de automonitoramento.

Em relação à interação entre linguística e literatura, a pesquisa em relato neste artigo elegeu a psicolinguística, buscando os pontos convergentes com a teoria da literatura para isso - a compreensão como condição para o prazer estético; a leitura como processo cognitivo de interação entre o texto, o autor e o leitor, numa dada situação de leitura; o texto literário como aberto a continuadas novas construções de sentidos resultantes das sucessivas sinapses cognitivas, donde a importância natural das antecipações; a leitura como uso de procedimentos preditivos e de reflexão metacognitiva sobre eles, como caminho para o horizonte de expectativas; e o apoio do processo de predição em pistas linguísticas, conhecimentos prévios e automonitoramento, condições para a constituição de processos conscientes, indispensáveis para a construção dos sentidos.

Por sua vez, a interação com a computação foi determinante para a geração de ferramenta de pesquisa, possibilitando a apresentação gradativa do texto ao leitor, denominado, aqui, de formato segmentado. Esse instrumento favoreceu a coleta de dados sobre os procedimentos utilizados pelos sujeitos, nesta pesquisa, e abre a possibilidade de seu uso em novas situações.

Cabe, assim, fechar o corpo dessas considerações, dando relevo à necessidade de confirmação de um espaço próprio de investigação da leitura do texto literário em abordagem que aproxime teoria, pesquisa e ensino, com foco nas convergências entre psicolinguística e teoria da literatura e apoio da computação, de modo a explicitar os processos cognitivos do leitor e, a partir dessas análises, apontar com sustentação linguístico-literária caminhos produtivos para o ensino da leitura.

\section{Prediction and reading comprehension of literary text sequences with dominant narratives}

\section{Abstract}

In this paper, the goal is to provide the reader interested in the dialogue theory, research and teaching, focusing on the psycholinguistic study on literary texts, the processes and research's results realized with the objective of examining the use of the prediction strategy and it relationships with performance in reading comprehension, literary text reading with dominant narratives sequences, and the reader's perceptions about the process done. The study, based in psycholinguistics in association with 
literature and technology support in computing had as subjects students from languages course and, as research tools, predictive testing procedures in continuous format, predictive testing procedures in segmented format, compreenshion testing and perceptions testing about the procedures performed (TPPR). The main results achieved are: the instruments for predictive analysis procedures (in both formats) built for this investigative situation, and the explanation of these procedures (and their connections with the comprehension) during the reading of three literary texts by beginners and concluding students of Languages ourse.

Keywords: Reading. Prediction and comprehension. Literary text.

\section{Nota}

1 Este artigo resulta de pesquisa realizada em 2011/2012 com apoio da FAPERGS, que teve como bolsista o graduando Charles Dall'Agnoll, como colaboradora, a mestranda Aline Job da Silva e como assessora, a Profa. Dr. Maria Tereza Amodeo.

\section{Referências}

ADAM, J. M. A Linguística textual. São Paulo: Cortez, 2008.

AMODEO, T.; PEREIRA, V. W. Linguística e teoria da literatura: uma interface possível. Letras de Hoje, Porto Alegre: Edipucrs, v. 45, n. 3, jul./set. 2010, p. 18-25.

CULLER, J. Teoria literária: uma introdução. São Paulo: Beca, 1999.

DEHAENE, S. Les neurones de la lecture. Paris: Odile Jacob, 2007.
ECO, U. Apocalípticos e integrados. São Paulo: Perspectiva, 1993.

FLÔRES, O. ; PEREIRA, V. W. Ensino da compreensão leitora: faces e interfaces psicolinguísticas. Linguarum Arena, Porto: FCT, v. 3 , p. $75-88,2012$.

GOMBERT, J. E. Metalinguistic development. Chicago: The University of Chicago Press, 1992.

GOODMAN, K. S. Reading: a guessing game. In: SINGER, H.; RUDDELL, R. B. (Eds.). Theoretical models and processes of reading. Newark, DE: International Reading Association, 1976. p. 497-508.

. Unidade na leitura - um modelo psicolinguístico transacional. Letras de Hoje, Porto Alegre: Edipucrs, n. 86, p. 9-43, dez. 1991.

INGARDEN, R. A obra de arte literária. Lisboa: FCG, 1965.

JAUS, H. R. A literatura como provocação. Lisboa: Vega, 1993.

PEREIRA, V. W. Arrisque-se... Faça o seu jogo. Letras de Hoje, Porto Alegre: Edipucrs, n. 128, p. 47-64, jun. 2002.

. Predição leitora e inferência. In: COSTA, J. C. da (Org.). Inferências linguísticas nas interfaces. Porto Alegre: EDIPUCRS, 2009, p. 10-22. Apresentação em CD.

. A predição na teia de estratégias de compreensão leitora" - Revista Confluência. Rio de Janeiro: Ed. Instituto de Língua Portuguesa, v. 1, p. 81-91, 2012.

PEREIRA, V. W.; PICCINI, M. Preditibilidade: um estudo fundado pela psicolinguística e pela informática. Letras de Hoje, Porto Alegre: Edipucrs, n. 144, p. 305-24, jun. 2006.

SMITH, F. Compreendendo a leitura. Porto Alegre: Artes Médicas, 2003. 